University of Nebraska - Lincoln

DigitalCommons@University of Nebraska - Lincoln

Faculty Papers and Publications in Animal

Science

Animal Science Department

August 1986

\title{
FACTORS INFLUENCING BEST ANNUAL RACING TIME IN FINNISH HORSES
}

\author{
M. Ojala \\ University of Helsinki, 00710 Helsinki, Finland \\ L. Dale Van Vleck \\ University of Nebraska-Lincoln, dvan-vleck1@unl.edu \\ R. L. Quaas \\ Cornell University
}

Follow this and additional works at: https://digitalcommons.unl.edu/animalscifacpub

Part of the Animal Sciences Commons

Ojala, M.; Van Vleck, L. Dale; and Quaas, R. L., "FACTORS INFLUENCING BEST ANNUAL RACING TIME IN FINNISH HORSES" (1986). Faculty Papers and Publications in Animal Science. 345.

https://digitalcommons.unl.edu/animalscifacpub/345

This Article is brought to you for free and open access by the Animal Science Department at DigitalCommons@University of Nebraska - Lincoln. It has been accepted for inclusion in Faculty Papers and Publications in Animal Science by an authorized administrator of DigitalCommons@University of Nebraska - Lincoln. 


\title{
FACTORS INFLUENCING BEST ANNUAL RACING TIME IN FINNISH HORSES ${ }^{1}$
}

\author{
M. Ojala, L. D. Van Vleck ${ }^{2}$ and R. L. Quaas ${ }^{2}$ \\ University of Helsinki ${ }^{3}$ \\ 00710 Helsinki, Finland
}

\begin{abstract}
The fixed effects of year of race, season of race, sex, method of start, annual number of starts, length of race and racetrack were evaluated on best annual racing time in Finnish Horses. Data included 1,378 records for 554 horses by 206 sires. Five models were assumed within the age groups from 3 to $6 \mathrm{yr}$. The annual number of starts, method of start and season of race effects were interrelated. An increase in number of starts was associated with considerable improvement in a horse's best annual racing time. Records should not, however, be adjusted for effect of annual number of starts because it would simultaneously account for part of genetic differences among horses. The largest estimates of heritability were obtained for best annual racing time when the model included the fixed year-season and sex effects. Corresponding to this model, the estimate of repeatability for best annual racing time over the four age groups was $.60 \pm .03$. An example of best linear unbiased predictions of sires' breeding values based on progeny records in one or several ages is presented.
\end{abstract}

(Key Words: Racehorses, Trotting, Racing Performance, Environmental Factors, Heritability, Repeatability.)

\section{Introduction}

In most countries racing associations routinely summarize individual race records for each horse on an annual basis and on the basis of the whole racing career. If data consisting of race records are used to select individuals for breeding purposes, records should be adjusted for pertinent environmental effects.

Data consisting of individual race records on trotters have been analyzed by several authors (Linner and Osterkorn, 1974; Katona and Osterkorn, 1977; Hintz and Van Vleck, 1978; Katona, 1979; Tolley et al., 1983) to estimate effects influencing the records. The studies show that numerous effects contribute to the outcome of a race. It is not obvious, however, for which effects and how these data should be adjusted when the object is breeding evaluation of trotters. When the data have been summarized

\footnotetext{
${ }^{1}$ This study was financially supported, in part, by the Finnish Trotting and Horse Breed. Assoc.

${ }^{2}$ Dept. of Anim. Sci., Cornell Univ, Ithaca, NY 14853.

${ }^{3}$ Dept. of Anim. Breed.

Received February 26, 1986.

Accepted August 28, 1986.
}

on an annual basis, the number and the interpretation of the factors influencing the best annual racing time obviously differ from those influencing time records in individual races.

The objective of this study was to evaluate the effect of the year of race, season of race, sex, method of start, annual number of starts, length of race and racetrack on best annual racing time in Finnish Horses.

\section{Materials and Methods}

Data. The original set of data consisted of individual race records made by Finnish Horses born in 1967 or 1968 that took part in trotting races at ages of 3 to $6 \mathrm{yr}$. The information in individual race records was summarized annually for each horse. A record used in this study was a. horse's best annual racing time, expressed in seconds per kilometer. There was a total of 1,378 records for 554 horses by 206 sires in the data. The numbers of horses having a record at $3,4,5$ or 6 yr of age were $216,362,373$ and 427.

In addition to a horse's age, the following information about fixed factors, which may influence a horse's best annual racing time, was available: 1 ) year of race: $2 \mathrm{yr}$ within each age group ; 2) season of race: coded from originally 
reported month of race as winter (months 1 to 4 ), summer (6 to 9 ), fall and spring ( 10 to 12 and 5); 3) sex: stallion, mare and gelding; 4) method of start: auto-start, which is a flying start behind a car, and volt-start in which horses are handicapped, based on total lifetime earnings or sometimes on best time in lifetime, by increments of $20 \mathrm{~m}$ behind the base distance ; 5) annual number of starts: coded in six groups as $1,2,3$ and $4 ; 5$ to $9 ; 10$ to 19 ; and $\geqslant 20$ starts; 6) length of race: coded as $<2,000 \mathrm{~m}$ and $\rangle$ $2,000 \mathrm{~m} ; 7$ ) racetrack: 11 individual tracks, and in addition 10 track groups formed from individual tracks on the basis of the location in the country.

Sire and Residual Variance Components. The data set was edited so that each sire was required to have at least two progeny in an age group. This resulted in a data set with 1,009 records. The numbers of horses in the four age groups were $151,259,278$ and 321 , respectively. There were, on average, five to six progeny per sire within an age group. These data were previously analyzed by Ojala and Van Vleck (1981) for 24 traits under the assumption of simple statistical models.

To estimate sire and residual variances, the data were analyzed using five different models. The linear model assumed within each age group was in general form:

$$
\mathbf{y}=\mathbf{X} \mathbf{b}+\mathbf{Z} \mathbf{s}+\mathbf{e},
$$

where

$\mathrm{y}$ is a $\mathrm{N} \times 1$ vector of horses' best annual racing times;

$\mathbf{X}$ and $\mathbf{Z}$ are known incidence matrices with $\mathrm{N}$ rows and $\mathrm{p}$ and $\mathrm{q}$ columns, respectively;

b is a vector of unknown fixed effects of length $\mathrm{p}$;

$\mathbf{s}$ is a $\mathrm{q} \times 1$ non-observable vector of random sire effects representing one-half of sires' breeding values and

$e$ is a $N \times 1$ non-observable vector of random residual effects.

It was assumed that the random vectors have null means and

$$
\operatorname{var}\left[\begin{array}{l}
\mathrm{s} \\
\mathrm{e}
\end{array}\right]=\left[\begin{array}{cc}
\mathrm{I} \sigma_{\mathrm{s}}^{2} & 0 \\
0 & I \sigma_{\mathrm{e}}^{2}
\end{array}\right] .
$$

The five models studied differed in the fixed part of equation [1] as follows:
Model 1 (full model)-b consisted of yearseason subclass, sex, method of start-length of race subclass, annual number of starts and racetrack effects;

Model 2-b consisted of year-season subclass, sex, method of start and annual number of starts effects;

Model 3-b consisted of year-season subclass, sex and method of start effects;

Model 4-b consisted of year-season subclass and sex effects;

Model 5 (simple model)-b consisted of general mean only.

Components of variance were estimated using least-squares (LS) equations in [2] based on equation [1] :

$$
\left[\begin{array}{cc}
x^{\prime} x & x^{\prime} z \\
z^{\prime} x & z^{\prime} z
\end{array}\right]\left[\begin{array}{l}
b \\
s
\end{array}\right]=\left[\begin{array}{l}
x^{\prime} y \\
z^{\prime} y
\end{array}\right]_{[2]}
$$

In order to perform calculations, sire effects (s) were temporarily considered fixed. This procedure results in variance components that are estimates of Henderson's method 3 (Searle, 1971). Using estimates of sire and residual variances, heritabilities $\left(h^{2}\right)$ of best annual racing time were estimated based on the intra-class correlation of paternal half-sibs. Approximate standard errors of heritabilities were calculated applying formulas 10.12 and 10.15 in Falconer (1981).

Estimation Effects of Fixed Factors. To estimate effects of fixed factors and to obtain correction factors for pre-adjusting the data, the LS equations in [2] were modified. A ratio of estimated variances $\left(\sigma_{\mathrm{e}}^{2} / \sigma_{\mathrm{s}}^{2}\right)$ was added to the diagonal elements of the $\mathbf{Z}^{\prime} \mathbf{Z}$ submatrix relating to the random sire effect in the equation [1]. This ratio of variances can be accounted for if an estimate of heritability for the trait is known. Heritability of .25 for best annual racing time was assumed. The modified LS equations, called the mixed model (MM) equations according to Henderson (1974), yield the same solutions as the generalized leastsquares (GLS) method. Consequently, estimable functions of the fixed effects in the model are best linear unbiased estimates (BLUE). The estimable function of interest in this study was a difference between the levels within a fixed factor, i.e., the effect of a level of a factor. 
These will be called differences later in this paper. The difference between two levels of a fixed factor was tested for statistical significance by the two-tailed $t$-test (Snedecor and Cochran, 1967). Variances of differences were calculated as shown by Searle (1971).

Horse and Residual Variance Components. The data set was edited so that each horse was required to have at least two records, i.e., a record in two or more of the four age classes. The data set for estimating horse and residual variances and repeatability of best annual racing time included 1,244 records on 420 horses. Components of variance were estimated for both pre-adjusted and unadjusted best annual racing times. Records were pre-adjusted for all other fixed effects in models 2 to 4, except for year-season effects. Additive adjustment factors were obtained by reversing the sign of the differences in solutions. The equation of the model was:

$$
\mathbf{y}=\mathbf{X} \mathbf{b}+\mathbf{Z} \mathbf{h}+\mathbf{e}
$$

where

$\mathbf{y}$ is a vector of pre-adjusted best annual racing times on horses aged 3 to $6 \mathrm{yr}$;

$\mathbf{X}$ and $\mathbf{Z}$ are known incidence matrices;

$\mathbf{b}$ is a vector of fixed age-year-season subclass effects;

$h$ is a vector of random horse effects representing the genetic effects and permanent environmental effects associated with a horse and

$e$ is a vector of random residual effects.

It was assumed that the random vectors have null means and

$$
\operatorname{var}\left[\begin{array}{l}
\mathbf{h} \\
\mathbf{e}
\end{array}\right]=\left[\begin{array}{ll}
\mathbf{I} \sigma_{\mathrm{h}}^{2} & 0 \\
\mathbf{0} & I \sigma_{\mathrm{e}}^{2}
\end{array}\right] .
$$

In computing the components of variance, horse effect was temporarily considered fixed. The estimate of repeatability ( $r$ ) for best annual racing time was the estimated intraclass correlation. The approximate standard error of repeatability was calculated according to Falconer (1981).

Sires' Breeding Values. Predictions of sires' breeding values within an age group were obtained jointly in the context of estimating differences between the levels of fixed factors. As obtained from the $M M$ equations, predictions of one-half of sires' breeding values are, according to Henderson (1974), best linear unbiased predictions (BLUP).

An overall prediction (across age groups) of a sire's breeding value may be obtained using repeated records on progeny. The model, based on Henderson (1977), was:

$$
\mathbf{y}=\mathbf{X} \mathbf{b}+\mathbf{Z}_{1} \mathbf{s}+\mathbf{Z}_{2} \mathbf{p}+\mathbf{e}
$$

where

$\mathbf{y}$ is a vector of pre-adjusted best annual racing times on sires' progeny for any of the ages of 3 to $6 \mathrm{yr}$;

$\mathbf{X}, \quad \mathbf{Z}_{1}$ and $\mathbf{Z}_{2}$ are incidence matrices for fixed effects, sires and progeny, respectively;

b is a vector of fixed age-year-season effects,

$\mathbf{s}$ is a random vector of one half of sires' additive genetic values;

$\mathbf{p}$ is a random vector representing the genetic effects not accounted for in $\mathbf{s}$ and permanent environmental effects associated with the progeny of sires and

$\mathbf{e}$ is a random vector of residual effects.

The random vectors, $\mathbf{s}, \mathbf{p}$ and $\mathbf{e}$, were assumed to have null means and variance-covariance matrices I $\sigma_{\mathrm{s}}^{2}=\mathrm{I} .25 \mathrm{~h}^{2} \sigma_{\mathrm{y}}^{2}, \mathrm{I} \sigma_{\mathrm{p}}^{2}=\mathrm{I}\left(\mathrm{r}-.25 \mathrm{~h}^{2}\right)$ $\sigma_{\mathrm{y}}^{2}$ and $\mathrm{I} \sigma_{\mathrm{e}}^{2}=\mathrm{I}(1-\mathrm{r}) \sigma_{\mathrm{y}}^{2}$, respectively. It was also assumed that $\operatorname{cov}\left(\mathbf{s}, \mathbf{p}^{\prime}\right)=\operatorname{cov}\left(\mathbf{s}, \mathbf{e}^{\prime}\right)=$ $\operatorname{cov}\left(\mathbf{p}, \mathbf{e}^{\prime}\right)=\mathbf{0}$.

Estimates of $h^{2}=.25$ and $r=.50$ were assumed. Thus, the following ratios of variances $\sigma_{\mathrm{e}}^{2} / \sigma_{\mathrm{s}}^{2}=8$ and $\sigma_{\mathrm{e}}^{2} / \sigma_{\mathrm{p}}^{2}=1.143$ were added in diagonal elements of sire $x$ sire and progeny $x$ progeny submatrices on the left-hand side of the normal equations as shown by Henderson (1977).

\section{Results and Discussion}

Estimates of Sire and Residual Variances. Model 1 represented the full model, including the following fixed effects: year-season, sex, method of start-length of race, number of starts and racetrack. Model 1 resulted in the smallest residual variance for best annual racing time in each age group (table 1). Omitting the racetrack and length of race effects from model 1 increased the estimate of residual variance only slightly (model 2 ). Sire variances were similar in 
magnitude for models 1 and 2. These two statements apply for all age groups except 3 -yr-olds. Omission of the number of starts effect from model 2 resulted in a marked increase in both sire and residual variances (model 3). This implies that the annual number of starts effect is associated with both additive genetic and environmental effects influencing a horse's best annual racing time. Omitting the method of start effect from model 3 resulted in a slight increase in both sire and residual variances (model 4). Residual variance for best annual racing time was largest when the model included only the fixed effect of the general mean (model 5). The statements regarding models 4 and 5 apply for all age groups except 3 -yr-olds.

No general pattern could be drawn about sire and residual variances in the different age groups. This may be due to the limited number of records and partly to different samples of sires in the four age groups.

Estimates of heritability were largest when based on models 3 and 4 . In other words, the magnitude of heritabilities was the largest, about .50 on average, when models included year-season and sex or these and method of start as fixed effects (table 2).
Estimates of heritability were associated with large standard errors (table 2). Consequently, the estimated heritabilities are of little value as estimates of parameter values. The merit of the estimated variance components and heritabilities in this study is that they give intimations about the nature of influences of the fixed factors included in the different models.

Effects of Fixed Factors. Racetrack and length of race effects did not account for much of the variation in best annual racing time (table 1). This is in accord with the concept that track effect does not apply well to data consisting of horses' best annual racing times. This is partly due to the specific feature attached to a horse's best annual racing time: it is required that several of the favorably contributing factors occur simultaneously; timing of a horse's peak performance obviously has a major influence. Thus, in such data, the track effect mainly represents the quality of horses to which races are being offered on a particular track. Horses' best annual racing times, expressed in seconds per kilometer, improved as the length of race increased. Only a contrary result would have supported adjusting for this effect. The discrepancy is partly ex-

TABLE 1. ESTIMATES OF SIRE AND RESIDUAL VARIANCES FOR BEST ANNUAL RACING TIMEa

\begin{tabular}{|c|c|c|c|c|}
\hline \multirow{2}{*}{$\begin{array}{l}\text { Model }{ }^{b} \text { and source } \\
\text { of variance }\end{array}$} & \multicolumn{4}{|c|}{$\begin{array}{c}\text { Estimates of variance components } \\
\text { by age of horse }\end{array}$} \\
\hline & $3 \mathrm{yr}$ & $4 \mathrm{yr}$ & $5 \mathrm{yr}$ & $6 \mathrm{yr}$ \\
\hline \multicolumn{5}{|c|}{ Model 1: (A, B, C, D, E) } \\
\hline Sire & 3.2 & 2.8 & .9 & 6.7 \\
\hline Residual & 62.4 & 41.2 & 24.8 & 26.0 \\
\hline \multicolumn{5}{|l|}{ Model 2: $(A, B, D, F)$} \\
\hline Sire & 1.1 & 2.6 & 1.0 & 6.0 \\
\hline Residual & 76.4 & 47.4 & 25.8 & 29.1 \\
\hline \multicolumn{5}{|l|}{ Model 3: $(A, B, F)$} \\
\hline Sire & 9.3 & 8.3 & 3.4 & 16.0 \\
\hline Residual & 106.7 & 83.3 & 45.6 & 46.8 \\
\hline \multicolumn{5}{|l|}{ Model 4: $(A, B)$} \\
\hline Sire & 9.5 & 8.9 & 5.4 & 16.7 \\
\hline Residual & 105.8 & 86.3 & 52.9 & 59.1 \\
\hline \multicolumn{5}{|l|}{ Model 5: (G) } \\
\hline Sire & 8.8 & 11.4 & 6.0 & 15.3 \\
\hline Residual & 104.4 & 149.6 & 66.2 & 72.8 \\
\hline
\end{tabular}

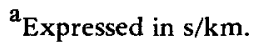

${ }^{b}$ Fixed effects in the models are: year-season (A), sex (B), method of start-length of race (C), number of starts (D), race track (E), method of start (F), general mean (G).
} 
TABLE 2, ESTIMATES OF HERITABILITY $\left(h^{2}\right)$ AND APPROXIMATE STANDARD ERRORS (SE) FOR BEST ANNUAL RACING TIME

\begin{tabular}{|c|c|c|c|c|c|c|c|c|c|}
\hline \multirow[b]{3}{*}{ Modelâ } & \multicolumn{8}{|c|}{ Age of horse, $y r$} & \multirow{3}{*}{$\begin{array}{l}\text { Avg } \\
\text { of } \\
h^{2}\end{array}$} \\
\hline & \multicolumn{2}{|c|}{3} & \multicolumn{2}{|c|}{4} & \multicolumn{2}{|c|}{5} & \multicolumn{2}{|c|}{6} & \\
\hline & $h^{2}$ & SE & $h^{2}$ & $\mathrm{SE}$ & $\mathrm{h}^{2}$ & SE & $\mathrm{h}^{2}$ & $\mathrm{SE}$ & \\
\hline Model 1: (A, B, C, D, E) & .20 & .27 & .25 & .20 & .15 & .19 & .82 & .23 & .36 \\
\hline Model 2: $(\mathrm{A}, \mathrm{B}, \mathrm{D}, \mathrm{F})$ & .06 & .24 & .21 & .19 & .15 & .19 & .69 & .22 & .28 \\
\hline Model 3: (A, B, F) & .32 & .28 & .36 & .21 & .28 & .20 & 1.02 & .24 & .50 \\
\hline Model 4: $(\mathrm{A}, \mathrm{B})$ & .33 & .28 & .37 & .21 & .37 & .21 & .88 & .23 & .49 \\
\hline Model 5: (G) & .31 & .28 & .28 & .20 & .33 & .21 & .70 & .22 & .41 \\
\hline
\end{tabular}

${ }^{a}$ Fixed effects in the models are: year-season (A), sex (B), method of start-length of race (C), number of starts (D), race track (E), method of start (F), general mean (G).

plained by the fact that a large number of horses had achieved their best annual racing time at a long distance on volt-start. For previous reasons, no adjustment for racetrack and length of race could be justified.

The annual number of starts effect was one of the major factors influencing a horse's best annual racing time (table 3 ). An increase in the number of starts was associated with a decrease, i.e., an improvement, in a horse's best annual racing time. This result is obvious because horses with several starts had more chances to express their potential speed than horses with a single or only a few starts. The statement may also be interpreted to suggest that poor quality horses acquire, in general, only a few starts. Some other reasons contributing to variation in annual number of starts are differences in soundness among horses, and in expertise and enthusiasm among owners and trainers of horses. Thus, both genetic and environmental effects obviously cause the number of starts among horses to vary, as implied through models 2 and 3 in tables 1 and 2 . To avoid removing additive genetic differences among horses, the number of starts effect was excluded from model 3.

Auto-start as a method of start was superior to volt-start (table 3 ). Although there is no doubt about the general validity of the result, it should be noted that not all horses had the opportunity to race on both methods of start. In addition, more races are being offered on volt-start than on auto-start. This is also implied through the relative number of horses having achieved their best annual racing time on the two methods of start. Although the influence of the method of start effect was substantial on best annual racing time (table 3), its influence on the magnitude of sire and residual variances (table 1) and heritabilities (table 2) was negligible, as implied through models 3 and 4. Another, and perhaps a more appropriate, way to account for the method of start effect would have been to treat best annual racing time based on the two methods of start as separate traits.

Of year-season and sex effects, only the season effect had a statistically significant influence on a horse's best annual racing time (table 3). The purpose of having the season effect in the model was to account indirectly for track condition. This effect would, however, apply better to a set of data consisting of individual race records. But when the data comprise race records summarized annually for horses, inclusion of the season effect in the model may not sufficiently serve its original purpose. This statement is partly based on the relationship between the annual number of starts and season effects. It is unlikely, for example, that horses with several starts in a year achieve their best annual racing time during the early part of the year. Connection between the two fixed effects was also implied through a marked increase in differences for year-season effects in model 3 after excluding the number of starts effect from model 2 (table 3 ). The method of start effect is also partially connected to the number of starts and season effects for the previous reasons. The results in the other age groups were consistent with those for five-year-old horses in table 3.

Estimates of Horse and Residual Variances. The smallest estimate for residual variance was 


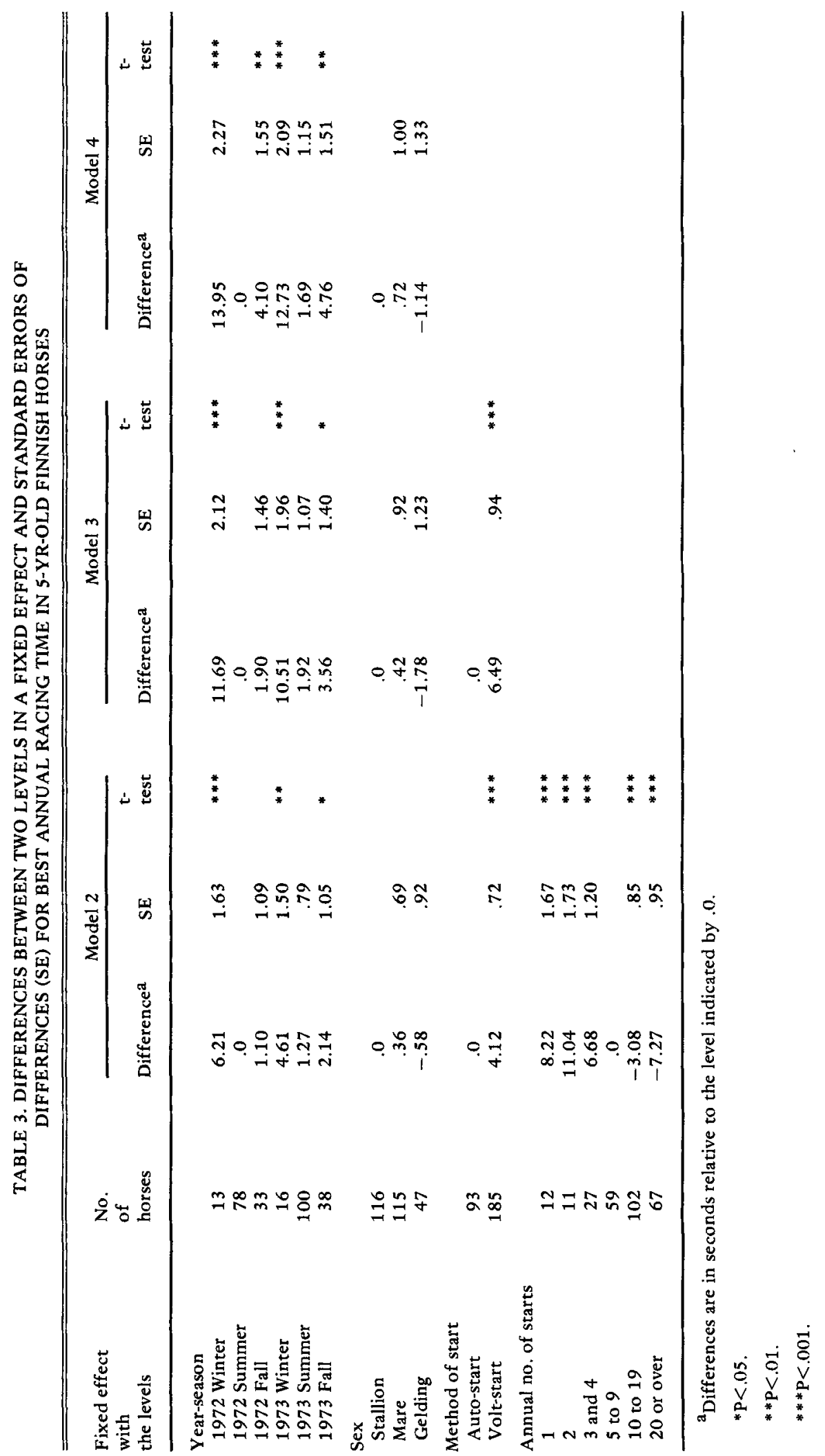


TABLE 4. ESTIMATES OF HORSE AND RESIDUAL VARIANCES, AND REPEATABILITIES (r) FOR BEST ANNUAL RACING TIME (BEST TIME)

\begin{tabular}{|c|c|c|c|c|}
\hline \multirow[b]{2}{*}{ Trait and model b } & \multicolumn{2}{|c|}{$\begin{array}{c}\text { Estimates of } \\
\text { variance due to }\end{array}$} & \multirow[b]{2}{*}{$\mathbf{r}$} & \multirow[b]{2}{*}{$\mathrm{SE}$} \\
\hline & Horse & Residual & & \\
\hline Best time pre-adjusted for $B, D$ and $F$ & 17.8 & 23.9 & .43 & .03 \\
\hline Best time pre-adjusted for $B$ and $F$ & 36.7 & 32.8 & .53 & .03 \\
\hline Best time pre-adjusted for $B$ & 44.4 & 29.8 & .60 &, 03 \\
\hline Best time (not pre-adjusted) & 43.8 & 30.2 & .59 & .03 \\
\hline
\end{tabular}

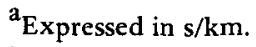

${ }^{b}$ Model including the fixed age-year-season effect was fitted on records pre-adjusted within age groups for the fixed sex (B), number of starts (D) and method of start $(F)$ effects from model 2, for $B$ and $F$ from model 3 and for $B$ from model 4 , respectively.
}

obtained when horses' best annual racing times were pre-adjusted for sex, method of start and number of starts effects (table 4). Pre-adjusting best annual racing time for these effects resulted also in the smallest estimate of horse variance. Thus, the number of starts effect accounted for both genetic and environmental differences in horses' best annual racing times. The most favorable ratio between these two components of variance, as represented by the largest estimate of repeatability, was obtained when the records had been pre-adjusted for sex. In this case, the estimate of repeatability for best annual racing time was $.60 \pm .03$.

Model of Choice. Prediction of sires' breeding values requires the records on progeny to be adjusted for appropriate fixed effects. For applications, the model should be as simple as possible. In selection of the model, the bias resulting from deleting factors from the model, as well as the magnitude of the variances of the estimates, should also be considered (Hocking, 1976).

The data in this study were not suitable for obtaining reliable estimates of genetic parameters, but may serve as a guide to achieve a better understanding of the nature of such data. The results were quite similar in the four age groups studied. Choosing the appropriate model from the different alternatives was complicated by the fact that both genetic and environmental effects were confounded with certain factors. The effect of number of starts had a major influence on both genetic, including the additive genetic, and environmental variation. If selection is for improving a horse's capacity for speed as characterized by best annual racing time, horses with an increasing number of starts in a year would be favored. This is fully in accord with a proper selection goal in breeding trotters.

Year and sex effects did not exert a significant influence on best annual racing time in this study. These effects should, however, be included in the model if evaluation of sires' breeding values is within an age group. The method of start effect should also be properly accounted for. This conclusion agrees with results for models used by Rönningen (1975) and Langlois (1984) in analyzing similar data.

Sires' Breeding Values. Predictions of sires' breeding values within each age group were obtained simultaneously with the estimation of effects of fixed factors for models 2 to 4 . Ranking of sires based on BLUP for one-half of sires' breeding values was quite consistent within an age group for the three models. Slight differences occurred between ranking of sires within the four age groups for model 4 (table 5). Sire evaluation, which was based on a combination of records at all ages, was parallel to those based on records of 5- and 6-yr-old progeny.

Both within-age-group and overall evaluations of sires are obviously useful for horsemen. This is supported by observations on a recent sire evaluation in which substantial differences occurred between the within-age-group evaluations for some sires (Ojala, 1985).

Additive relationships among the male ancestors of the progeny will be implemented, as shown by Henderson (1975), in the sire evaluation procedure. This would increase the accuracy of evaluations for sires having small progeny groups. The bias due to selection of 


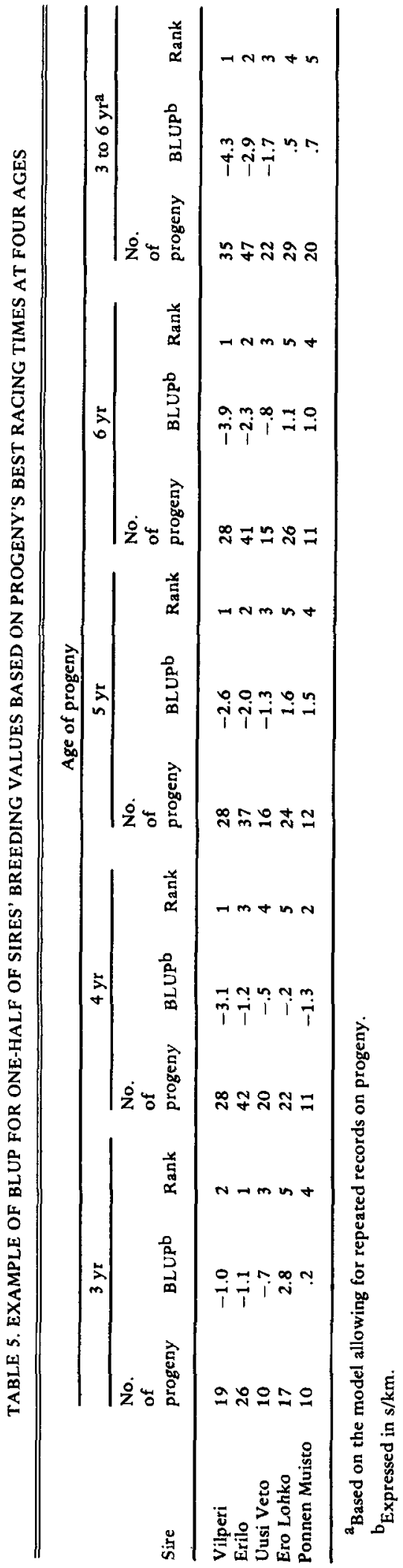

mates for the sires evaluated would also be reduced by including the maternal grandsire effect in a model. In addition, sire evaluations should also include other measures of racing performance, as traits based on earnings and placings, to supplement the best annual racing time.

\section{Literature Cited}

Falconer, D. S. 1981. Introduction to Quantitative Genetics (2nd Ed.). Longman Inc., New York.

Henderson, C. R. 1974. General flexibility of linear model techniques for sire evaluation. J. Dairy Sci. $57: 963$.

Henderson, C. R. 1975. Inverse of a matrix of relationships due to sires and maternal grandsires. $J$. Dairy Sci. 58:1917.

Henderson, C. R. 1977. Prediction of future records. In: E. Pollak, O. Kempthorne and T. B. Bailey, Jr. (Ed.) Proc. Int. Conf. Quantitative Genet. pp 615-638. Iowa State Univ. Press, Ames.

Hintz, R. L. and L. D. Van Vleck. 1978. Factors influencing racing performance of the Standardbred pacer. J. Anim. Sci. 46:60.

Hocking, R. R. 1976. The analysis and selection of variables in linear regression. Biometrics 32:1.

Katona, Ö. 1979. Environmental factors influencing the racing performance of the German trotter. Paper, 30th Annu. Meet. Eur. Assoc. Anim. Prod.

Katona, Ö. and K. Osterkorn. 1977. Genetischstatistische Auswertung des Leistungsmerkmals Rennzeit in der deutschen Traberpopulationen. Züchtungskunde 49:185.

Langlois, B. 1984. Heritability and genetic correlations for best racing times and earnings in 2-6 year old French Trotters (in French with English summary). Paper, 35th Annu. Meet. Eur. Assoc. Anim. Prod.

Linner, M.Th. and K. Osterkorn. 1974. Züchterische Auswertung der Rennleistung von Traberpferden der Jahrgänge 1963 und 1964 in der BRD. Züchtungskunde 46:168.

Ojala, M. 1985. Sire index for trotters (in Finnish). Hevosurheilu 61: No. 34.

Ojala, M. J. and L. D. Van Vleck. 1981. Measures of racetrack performance with regard to breeding evaluation of trotters. J. Anim. Sci. 53:611.

Rönningen, K. 1975. Genetic and environmental factors for traits in the North-Swedish trotter. $Z$. Tierz. Züchtungsbiol. 92:164.

Searle, S. R. 1971. Linear Models. John Wiley and Sons, Inc., New York.

Snedecor, G. W. and W. G. Cochran. 1967. Statistical Methods (6th Ed.). Iowa State College Press, Ames.

Tolley, E. A., D. R. Notter and T. J. Marlowe. 1983. Heritability and repeatability of speed for 2- and 3-year-old Standardbred racehorses. J. Anim. Sci. 56: 1294. 